\title{
Line of Sight Estimation Accuracy Improvement using Depth Image and Ellipsoidal Model of Cornea Curvature
}

\author{
Kohei Arai ${ }^{1}$ \\ 1 Graduate School of Science and Engineering \\ Saga University \\ Saga City, Japan
}

\author{
Kohya Iwamura ${ }^{1}$ \\ 1 Graduate School of Science and Engineering \\ Saga University \\ Saga City, Japan
}

\begin{abstract}
Line of sight estimation accuracy improvement is attempted using depth image (distance between user and display) and ellipsoidal model (shape of user's eye) of cornea curvature. It is strongly required to improve line of sight estimation accuracy for perfect computer input by human eyes only. The conventional method for line of sight estimation is based on the approximation of cornea shape with ellipse function in the acquired eye image. The proposed estimation method is based on the approximation of crystalline lenses and cornea with ellipsoidal function. Therefore, much accurate approximation can be performed by the proposed method. Through experiments, it is found that depth images are useful for improvement of the line of sight estimation accuracy.
\end{abstract}

Keywords-Computer input just by sight; Computer input by human eyes only; Purkinje image; Cornea curvature

\section{INTRODUCTION}

There are some methods which allow gaze estimations and its applications for Human Computer Interaction: HCI [1]-[31]. Paper [9] describes the method for gaze detection and line of sight estimation. In the paper, an error analysis is made for the previously proposed method. For the method, an expensive stereo camera is not needed, but only a cheap simple eye camera permits a motion of a user, and the method of determining the direction of a look from a pupil center and a cornea center of curvature is proposed without the calibration which forces a user a gaze of three points.

By specifically measuring an eyeball cornea curvature radius simply, the degree estimation of eyeball rotation angle which does not need a calibration is performed, details are extracted from a face picture, the posture of a head is detected from those relative spatial relationships, and a motion of a head is permitted. The light source of two points is used for measurement of the cornea curvature radius of an eyeball, and two Purkinje images obtained from the cornea surface were used for it. It is decided to also use together the near infrared light source which a camera has using the near-infrared camera which became budget prices, and to acquire the clear Purkinje image in recent years.

One of the weak points of the existing method for gaze estimation is that line of sight estimation accuracy is not so high when user moves away from the display and getting close to the display. Also, ellipse model of cornea shape is not so appropriate for human eyes. In the paper, these two problems are solved and overcome using raging image (Kinect acquires the depth between user and the display) and ellipsoidal shape model for estimation of cornea curvature.

The following section describes the proposed line of sight estimation accuracy improvement followed by some experiments. Then conclusions are described together with some discussions and future research works.

\section{PROPOSED METHOD}

\section{A. Eye Model}

Fig.1 (a) shows eye shape model while Fig.1 (b) shows the definitions of Purkinje images of the first to the fourth Purkinje images. The size and the curvature of cornea, sclera, retina, and eyeball are different for everybody. Therefore, calibration is required before using computer input just by sight. It is possible to estimate the size and the curvature by using the locations of the first to the fourth Purkinje images. The line of sight is defined as the line starting from the cornea curvature center which is estimated with Purkinje images to pupil center.
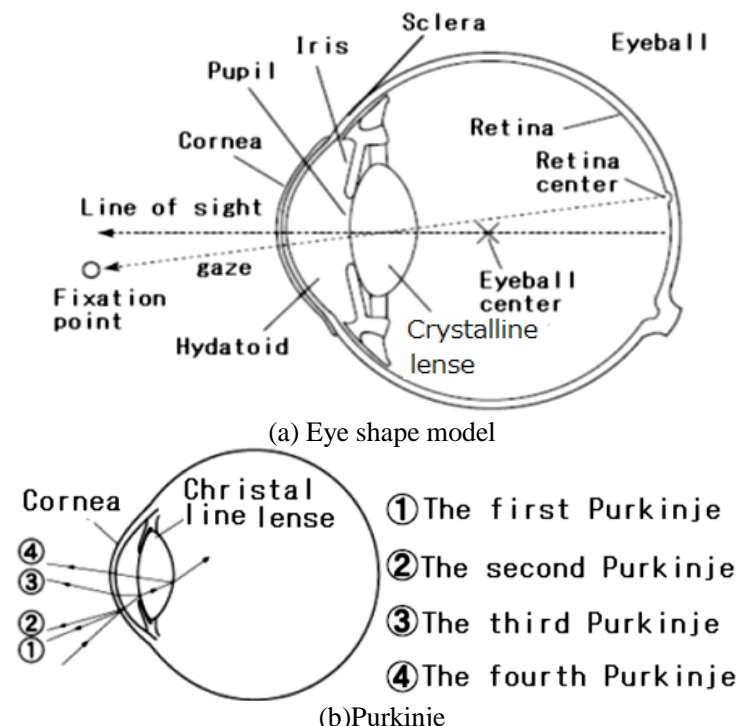

Fig. 1. Eye model and Purkinje images 


\section{B. Procedure for Estimation of Gaze Location on Display at Which User is Looking}

The procedure for estimation of gaze location on display at which user is looking is as follows,

1) Cornea curvature radius is estimated with double Purkinje images

2) Pupil center is determined with ellipse approximation of pupil shape

3) Cornea curvature center is determined with geometric relations among eyeball, camera, display and light sources (See Appendix),

4) Line of sight is determined with the cornea curvature center and pupil center

5) Gaze location on the display is determined with the line of sight vector

Fig. 2 shows the method for estimation of cornea curvature center and radius.

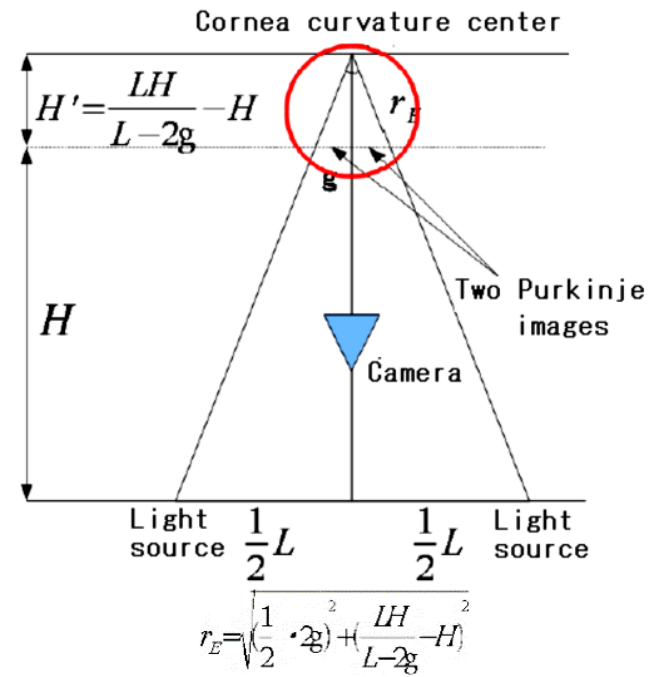

$L$ : Distance between two light sources $H$ : Distance between camera and eyeball $g$ : Distance between two Purkinje images $r_{E}$ : Cornea curvature radius

Fig. 2. Method for estimation of cornea curvature center and radius

$L$ and $H$ are given. The distance between two Purkinje images can be measured as follows,

1) binarize the acquired NIR image of the eye and its surroundings,

2) isolated noise pixels are removed by using morphological filter,

3) the distance between the locations of two Purkinje images is measured

This procedure is illustrated in the Fig.3. Thus, the cornea curvature radius can be estimated.

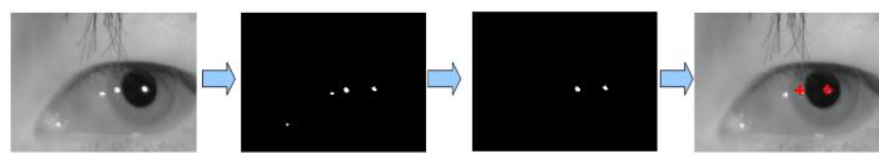

Fig. 3. Procedure of the cornea curvature radius measurement
Distance between two light sources, Distance between camera and eyeball, Distance between two Purkinje images, Cornea curvature radius can be derived from the following equation representing the cornea curvature radius.

$$
\mathrm{r}_{\mathrm{E}}=\sqrt{ }\left\{\mathrm{g}^{2}+[\{\mathrm{LH} /(\mathrm{L}-2 \mathrm{~g})\}-\mathrm{H}]^{2}\right\}
$$

\section{Improvement of Gaze Location Estimation Accuracy with} Depth Images Using Kinect

Fig.4 shows the set-up configuration of the proposed gaze location estimation with Kinect. Major specification and outlook of Kinect (v2) is shown in Table 1 and Fig.5, respectively. Meanwhile, major specification of NIR camera of DC-NCR13U is shown in Table 2.
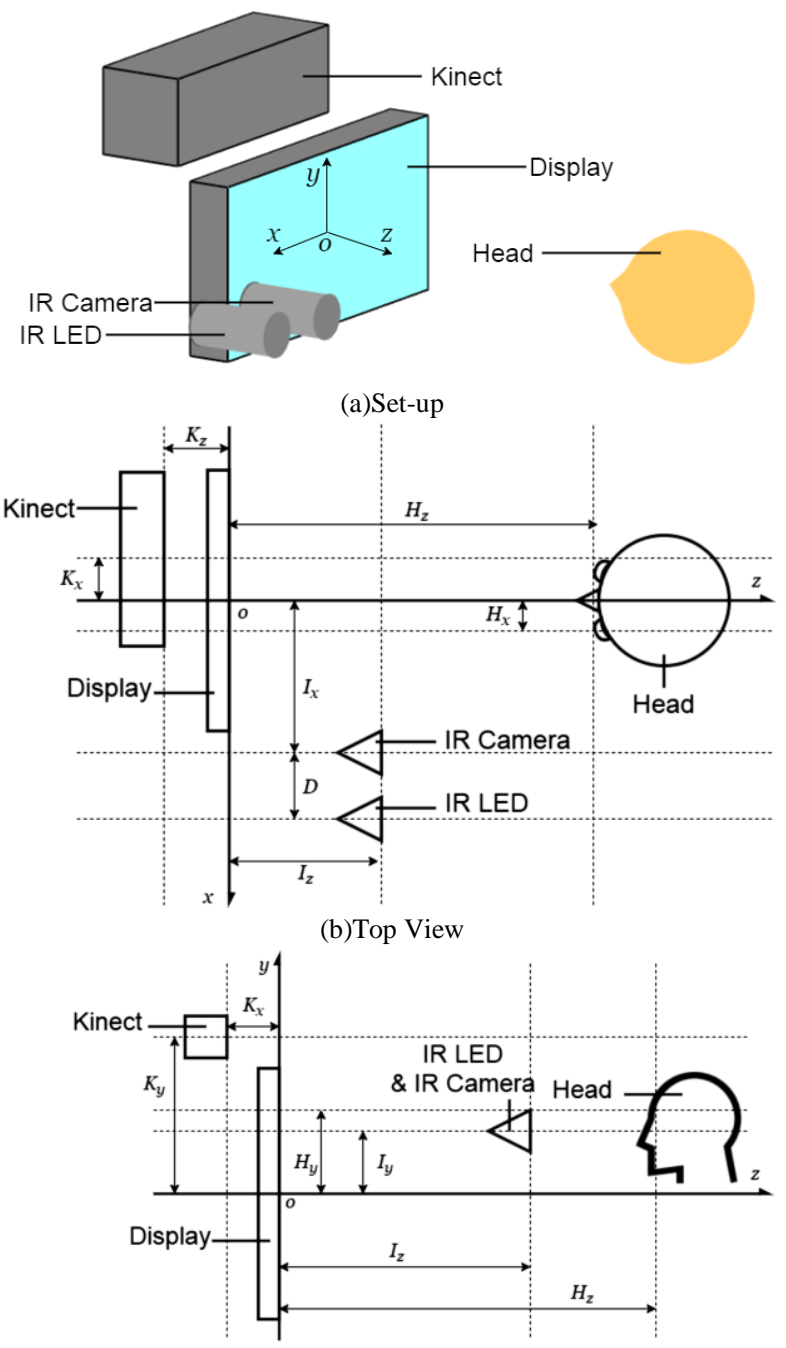

(c)Side View

Fig. 4. Set-up configuration of the proposed gaze location estimation with Kinect

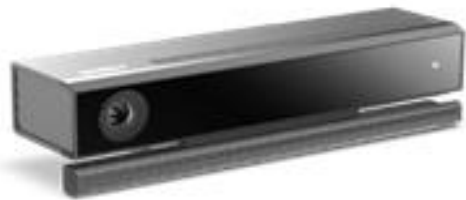

Fig. 5. Outlook of the Kinect (v2) 
TABLE I. MAJOR SPECIFICATION OF KINECT (V2)

\begin{tabular}{|c|c|c|}
\hline Color_image & $1920 \times 1080$ & fps:30 \\
\hline Depth_image & $512 \times 424$ & fps:30 \\
\hline Field_of_View & Horizontal:70[deg.] & Vertical:60[deg.] \\
\hline Depth_Range & $0.5 \sim 8.0[\mathrm{~m}]$ & \\
\hline
\end{tabular}

TABLE II. MAJOR SPECIFICATION OF NIR CAMERA(DC-NCR13U)

\begin{tabular}{|l|l|}
\hline Resolution & 1280x1024 \\
\hline fps & SXGA:7.5_VGA:30 \\
\hline Field-of-View(Horizontal) & 78[deg.] \\
\hline
\end{tabular}

On the other hand, Dlib which is developed by Davis E. King in 2002 is used for face detection function

\section{Dib C++ Library}

Also, Open_CV is used for image acquisition and manipulations.

\section{Preliminary Experiments}

The proposed procedure for estimation of line of sight (Gaze location on display is as follows,

1) IR image is acquired with DC-NCR-13U of NIR camera with NIR LED

a) Pupil center and Purkinje image center is detected from the acquired image

2) NIR image and depth image is acquired with Kinect

a) Iris is detected from the acquired depth image

b) Distance between the iris and Kinect is estimated with the depth image

c) Distance between the iris and display is estimated with the depth image

3) Cornea curvature center is estimated

4) Lune of sight (gaze location on the display) is estimated

Fig.6 (a) shows an example of eye image extracted with Dlib software tool. The extracted eye image is binarized and labeled image is created from the binarized image. Then ellipse matching is performed through function matching. Finally, iris center is detected as shown in Fig.6 (b). Meanwhile, Purkinje center is detected with the binarized image derived from the acquired original eye image as shown in Fig.6 (c).

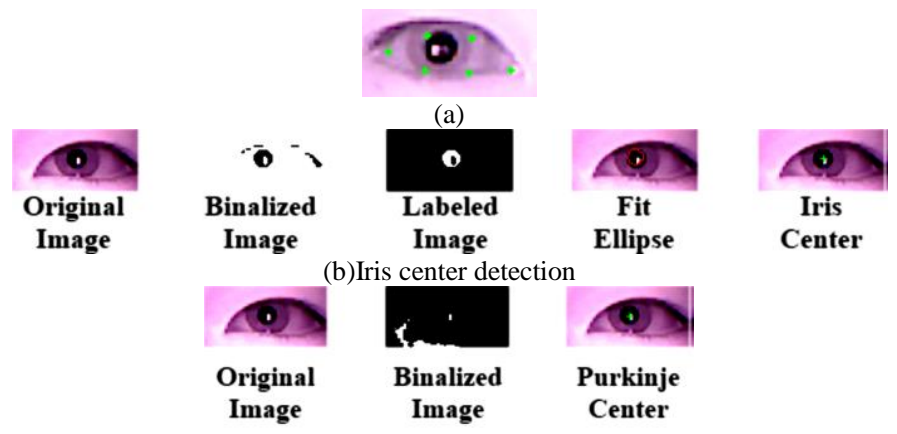

(c)Purkinje center detection

Fig. 6. Examples of iris and Purkinje center detection
Next thing we have to do is to estimate the distance between the iris and Kinect. Four points surrounding iris are detected from the acquired NIR image. Four points are assumed to be situated in a same plane. Same four points are corresponding to four points in the acquired depth image as shown in Fig.7.

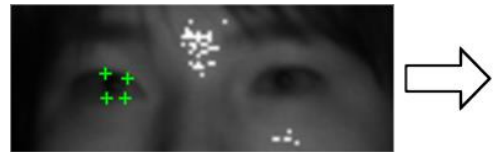

(a)NIR image

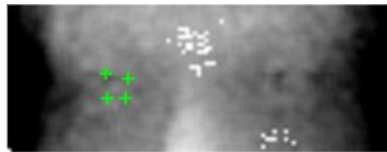

(b)Depth image
Fig. 7. Estimation of the distance between iris and Kinect

Distance between camera and pupil can be expressed in equation (2) which is related to the distance between Kinect and pupil.

$D_{\text {camera-pupil }}=H z-I z=(K z+H z)-K z-I z=D_{\text {kinect-pupil }}-(K z+I z)$

In accordance with the Fig.8, NIR image coordinate system can be converted to NIR camera coordinate system.

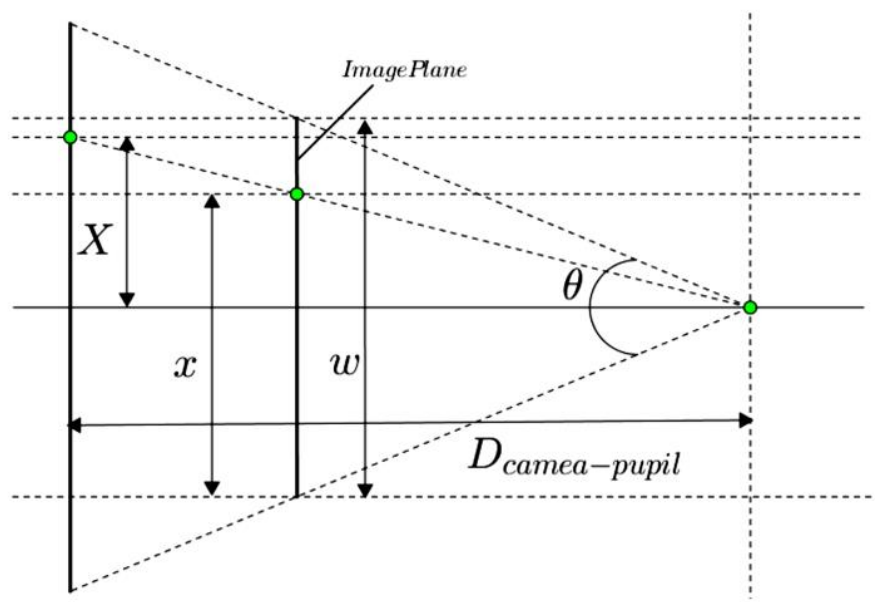

Fig. 8. NIR image coordinate system can be converted to NIR camera coordinate system.

Thus, $\mathrm{X}$ is calculated with the equation (3).

$$
\mathrm{X}=\mathrm{D}_{\text {camera-pupile }} \tan [(\theta / 2)\{(\mathrm{x}-\mathrm{w} / 2) / \mathrm{w} / 2\}]
$$

Next thing we have to do is to estimate cornea curvature center. Using the geometrical relation among NIR camera, NIR LED and Purkinje image center which is illustrated in Fig.9, cornea curvature center is estimated in the equation (4) because cornea curvature center is situated on the line which divide the angle among Purkinje image center, NIR camera and NIR LED.

$$
\begin{aligned}
& \mathrm{PE}=-\mathrm{CP}-\mathrm{LP} \\
& \mathrm{PO}=-\mathrm{R}(\mathrm{PE} / \mathrm{PE} \mid) \\
& \mathrm{CO}=\mathrm{CP}+\mathrm{PO}
\end{aligned}
$$




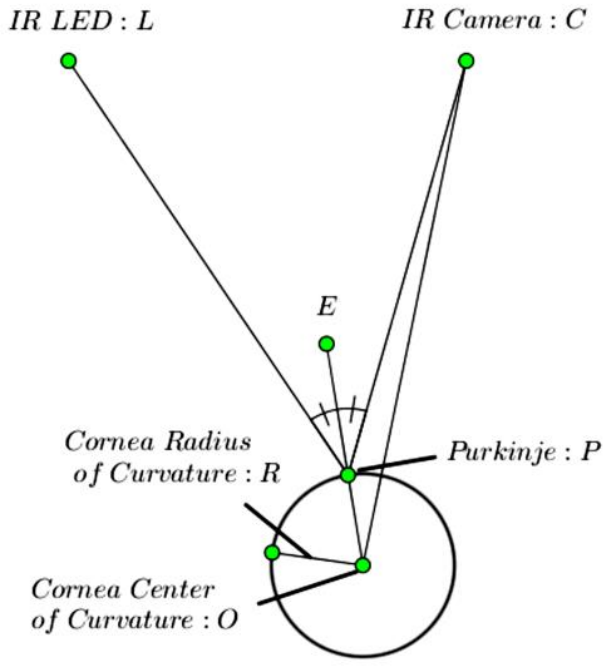

Fig. 9. Geometrical relation among NIR camera, NIR LED and Purkinje image center

Line of sight vector $\mathrm{V}$ is defined as the vector which is situated on the line $\mathrm{G}$ of pupil center and cornea curvature center $\mathrm{O}$ as shown in the equation (5).

$$
\mathrm{G}=\mathrm{O}+\mathrm{tV}
$$

where $\mathrm{t}$ denotes mediating variable. $\mathrm{Z}$ axis at the gaze location on display has to be zero. Therefore,

$$
0=\mathrm{O}_{\mathrm{z}}+\mathrm{tV}_{\mathrm{z}}
$$

Thus, the gaze location in unit of $\mathrm{mm}$ is expressed as the equation (7).

$$
\begin{gathered}
\left|\mathrm{G}_{\mathrm{x}}\right|=\left|\mathrm{O}_{\mathrm{x}}\right|+\mathrm{t}\left|\mathrm{V}_{\mathrm{x}}\right| \\
\left|\mathrm{G}_{\mathrm{y}}\right|\left|\mathrm{O}_{\mathrm{y}}\right| \quad\left|\mathrm{V}_{\mathrm{y}}\right| \\
=\left|\mathrm{O}_{\mathrm{x}}\right|+\left|-\mathrm{O}_{\mathrm{z}}\right|\left|\mathrm{V}_{\mathrm{x}}\right| \\
\left|\mathrm{O}_{\mathrm{y}}\right| \quad\left|\mathrm{V}_{\mathrm{z}}\right|\left|\mathrm{V}_{\mathrm{y}}\right|
\end{gathered}
$$

Also, gaze location in unit of pixel is represented as the equation (8).

$$
\begin{aligned}
& \left|\mathrm{g}_{\mathrm{x}}\right|=(\mathrm{dpi} / 25.4)\left|\mathrm{G}_{\mathrm{x}}\right|+\mid \text { width} / 2 \mid \\
& \left|g_{y}\right| \quad\left|G_{y}\right| \text { height } / 2 \mid
\end{aligned}
$$

where dpi, width, height is defined as dot per inch, display width and display height, respectively.

\section{EXPERIMENTS}

Cornea radius is assumed to be $7.92 \mathrm{~mm}$ for the previous experiences. The distance between iris and display is varied from 300,310 and $320 \mathrm{~mm}$. 20 trials rare conducted for each distance. The estimated gaze locations and ideal viewpoint are scattered as shown in Fig.10.

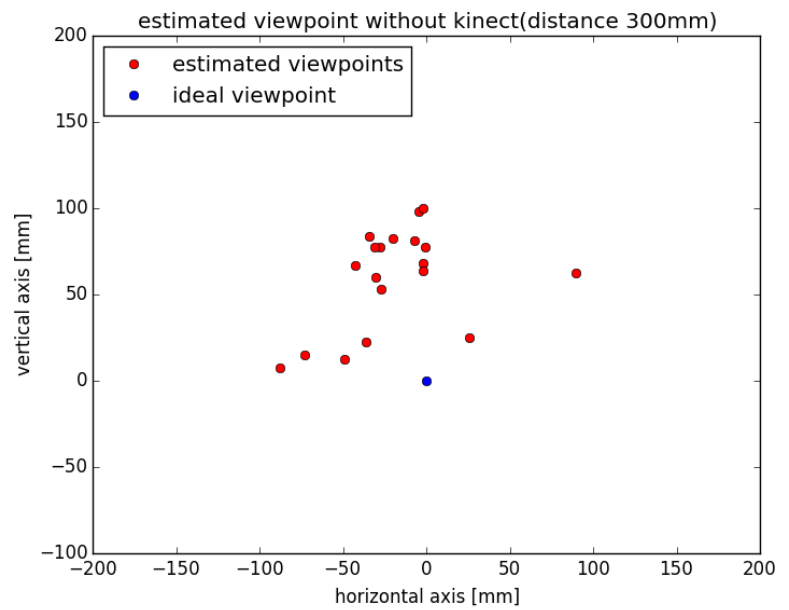

(a)Without Kinect (300mm)

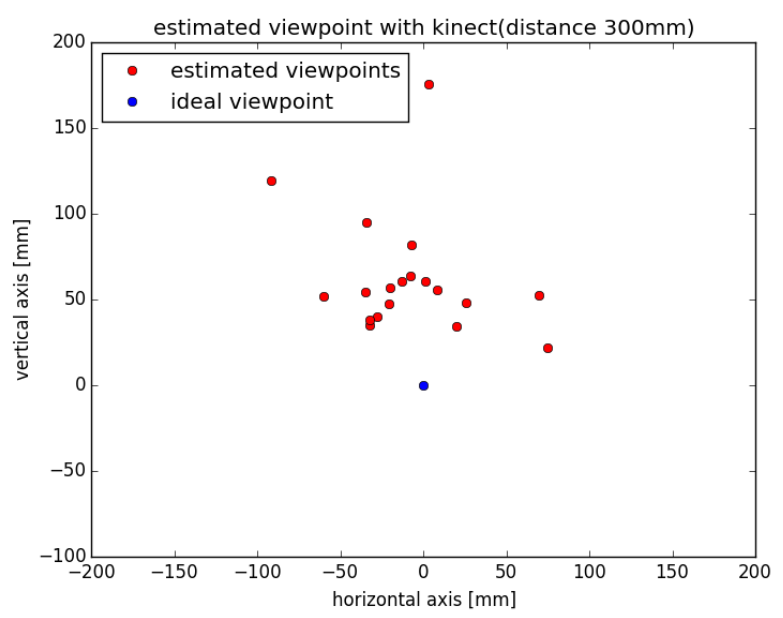

(b)With Kinect (300mm)

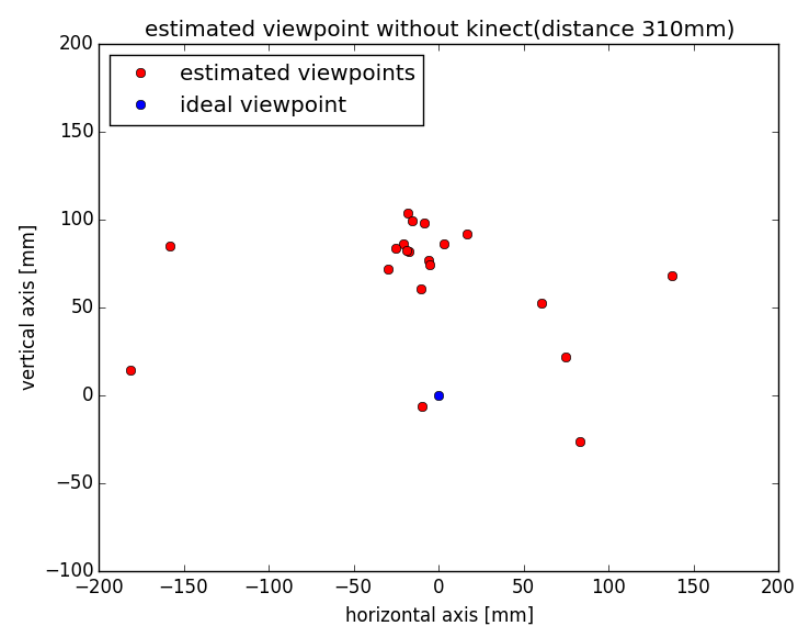

(c)Without Kinect (310mm) 


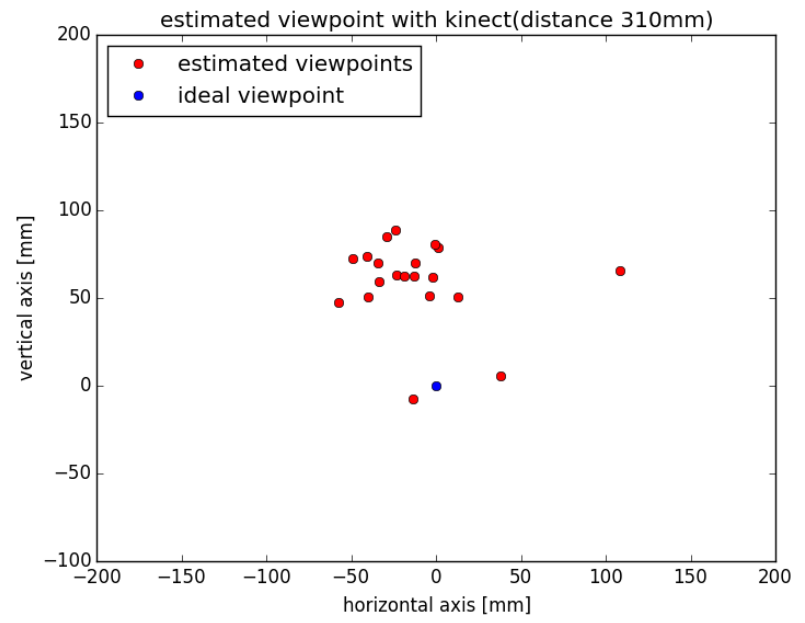

(d)With Kinect (310mm)

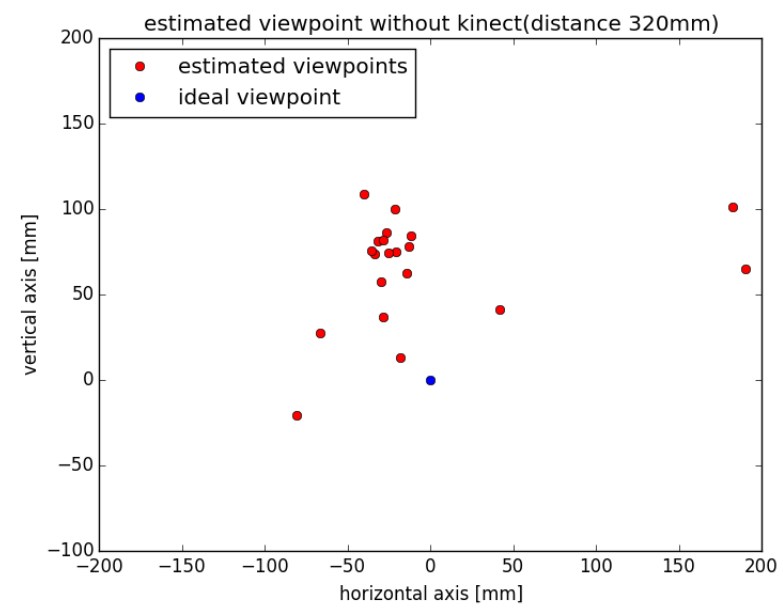

(e)Without Kinect $(320 \mathrm{~mm})$

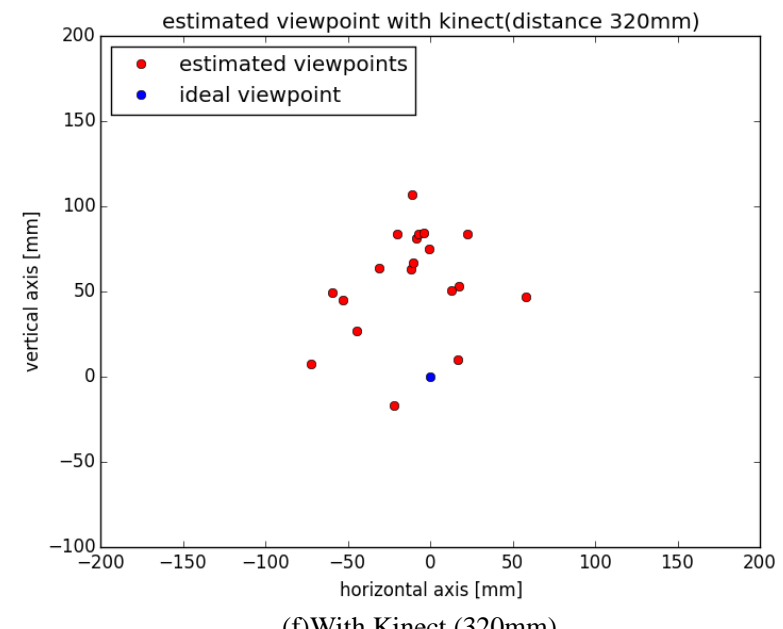

(f)With Kinect (320mm)

Fig. 10. Estimated gaze location and ideal viewpoint

It is found that the estimated gaze locations without Kinect are scattered much diversely compared to those with Kinect obviously.
Gaze location estimation errors in unit of degree and pixel are shown in Table 3 (a) and (b), respectively.

TABLE III. GAZE Location ESTIMATION ERROR IN UNit OF DegreE (A) AND PIXEL (B)

(a)Degree

\begin{tabular}{|l|l|l|l|l|}
\hline \multirow{2}{*}{$\begin{array}{l}\text { Distance } \\
{[\mathrm{mm}]}\end{array}$} & With & Kinect & Withyout & Kinect \\
\cline { 2 - 5 } & ErrorH(Deg.) & ErrorV(Deg.) & ErrorH(Deg.) & ErrorV(Deg.) \\
\hline 300 & 20.86 & 4.25 & 18.91 & 7.141 \\
\hline 310 & 14.86 & 5.81 & 16.71 & 10.53 \\
\hline 320 & 10.14 & 5.27 & 16.75 & 9.42 \\
\hline \multicolumn{4}{|c|}{ (b)Pixel } \\
\hline
\end{tabular}

\begin{tabular}{|l|l|l|l|l|l|}
\cline { 2 - 6 } \multicolumn{1}{c|}{} & \multirow{2}{*}{$\begin{array}{l}\text { Distance } \\
(\mathrm{mm})\end{array}$} & \multicolumn{2}{|c|}{ With Kinect } & \multicolumn{2}{l|}{ Without Kinect } \\
\cline { 2 - 6 } & Horizontal & Vertical & Horizontal & Vertical \\
\hline \multirow{4}{*}{ Average } & 300 & 43.21 & 64.84 & 46.85 & 62.28 \\
\cline { 2 - 6 } & 310 & 27.77 & 60.36 & 44.97 & 68.65 \\
\cline { 2 - 6 } & 320 & 35.4 & 56.73 & 46.88 & 67.24 \\
\hline \multirow{4}{*}{$\begin{array}{l}\text { Standard } \\
\text { Deviation }\end{array}$} & 300 & 59.65 & 34.75 & 73.06 & 29.88 \\
\cline { 2 - 6 } & 310 & 24.51 & 21.22 & 53.08 & 28.63 \\
\cline { 2 - 6 } & 320 & 48.09 & 26.9 & 49.32 & 26.22 \\
\hline
\end{tabular}

Particularly, the gaze location estimation error is evaluated for mean and standard deviation. As a conclusion, it is found that estimation error of gaze location with Kinect (distance information can be used) is superior to that without Kinect by the factor of 10 to $100 \%$.

\section{CONCLUSION}

Line of sight estimation accuracy improvement is attempted using depth image (distance between user and display) and ellipsoidal model (shape of user's eye) of cornea curvature. Through experiments, it is found that depth images are useful for improvement of the line of sight estimation accuracy. Particularly, the gaze location estimation error is evaluated for mean and standard deviation. As a conclusion, it is found that estimation error of gaze location with Kinect (distance information can be used) is superior to that without Kinect by the factor of 10 to $100 \%$.

Further investigations are required for simultaneous estimation of cornea curvature center and cornea radius, noise removal of the depth image.

\section{APPENDIX: ELLIPSOIDAL APPROXIMATION OF THE SHAPE OF CHRISTALline LENSE AND CORNEA OF EYE}

The shape of crystalline and cornea of the eye is assumed to be ellipsoid and can be approximated with the acquired eye image and Purkinje images based on the proposed ellipsoidal model shown in the following figure (Fig.A1). In the figure, 3D object of the shape of the extracted eye in the 3D coordinate system $(\mathrm{x}, \mathrm{y}, \mathrm{z})$ can be expressed with $\lambda, \varphi, \theta$. The internal points of the ellipsoid is represented with the equation (A1).

$$
(\mathrm{a} / \mathrm{A})^{2}+(\mathrm{b} / \mathrm{B})^{2}+(\mathrm{c} / \mathrm{C})^{2}<1
$$

It can be re-expressed with the equation (A2). $\mathrm{a} / \mathrm{A}=\mathrm{r} \cos \beta \cos \alpha$ 


$$
\mathrm{b} / \mathrm{B}=\mathrm{r} \cos \beta \sin \alpha
$$

$$
\mathrm{c} / \mathrm{C}=\mathrm{r} \sin \beta
$$

where $\mathrm{o}<\mathrm{r}<1,-\pi<\alpha<\pi,-\pi / 2<\beta<\pi / 2$

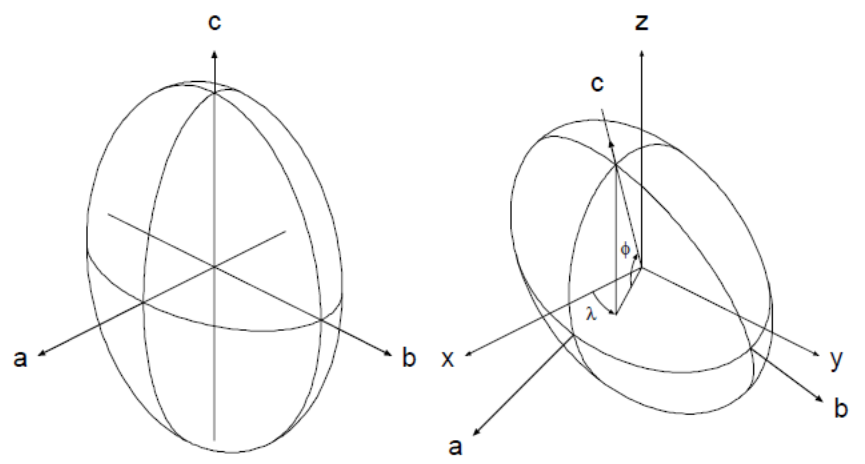

Fig.A1 Ellipsoidal model of the extracted eye (A3).

The volume of the ellipsoid is expressed with the equation

$$
\mathrm{V}=\iiint \mathrm{da} \mathrm{db} d \mathrm{c}=(4 \pi / 3) \mathrm{AB} \mathrm{C}
$$

The second order moment of the ellipsoid around the origin point is then expressed with the equation (A4).

$$
\mathrm{M}_{0}=\iiint\left(\mathrm{a}^{2}+\mathrm{b}^{2}+\mathrm{c}^{2}\right) \mathrm{da} \mathrm{db} \mathrm{dc}=(1 / 5) \mathrm{V}\left(\mathrm{A}^{2}+\mathrm{B}^{2}+\mathrm{C}^{2}\right)
$$

Also, the second order moments of ellipsoid around a, b, c axis can be represented with the equation (A5).

$M_{a}=\iiint\left(b^{2}+c^{2}\right) d a d b d c=(1 / 5) V\left(B^{2}+C^{2}\right)$

$\mathrm{M}_{\mathrm{b}}=\iiint\left(\mathrm{c}^{2}+\mathrm{a}^{2}\right) \mathrm{da} \mathrm{db} \mathrm{dc}=(1 / 5) \mathrm{V}\left(\mathrm{C}^{2}+\mathrm{A}^{2}\right)$

$M_{c}=\iiint\left(a^{2}+b^{2}\right) d a d b d c=(1 / 5) V\left(A^{2}+B^{2}\right)$

Meanwhile, the relation between $a, b, c$ axis and $x, y, z$ is expressed with the equation (A6).

$$
\begin{array}{ll}
|\mathrm{x}|=\Lambda \Phi \Theta|\mathrm{a}| \\
|\mathrm{y}| & |\mathrm{b}| \\
|\mathrm{z}| & |\mathrm{c}|
\end{array}
$$

Then the following three parameters are defined.

$$
\begin{aligned}
& \Lambda=|-\sin \lambda-\cos \lambda 0| \\
& |\cos \lambda-\sin \lambda 0| \\
& \left|\begin{array}{lll}
0 & 0 & 1
\end{array}\right| \\
& \Phi=\left|\begin{array}{lll}
1 & 0 & 0
\end{array}\right| \\
& |0 \sin \varphi-\cos \varphi| \\
& |0 \cos \varphi \sin \varphi| \\
& \Theta=|-\cos \theta \sin \theta \quad 0| \\
& |-\sin \theta-\cos \theta 0| \\
& \left|\begin{array}{lll}
0 & 0 & 1
\end{array}\right| \\
& \text { where }-\pi<\lambda<\pi,-\pi / 2<\varphi<\pi / 2,-\pi<\theta<\pi
\end{aligned}
$$

Then the unit vectors in the directions of a. b, c axis are defined with the equation (A8).

$$
\begin{array}{r}
\mathrm{e}_{\mathrm{a}}=\Lambda \Phi \Theta|1|=|\sin \lambda \cos \theta+\cos \lambda \sin \varphi \sin \theta| \\
|0||-\cos \lambda \cos \theta+\sin \lambda \sin \varphi \sin \theta| \\
|0| \mid-\cos \varphi \sin \theta
\end{array}
$$

$$
\begin{array}{r}
\mathrm{e}_{\mathrm{b}}=\Lambda \Phi \Theta|0|=|-\sin \lambda \sin \theta+\cos \lambda \sin \varphi \cos \theta| \\
|1||\cos \lambda \sin \theta+\sin \lambda \sin \varphi \cos \theta| \\
|0| \mid-\cos \varphi \cos \theta \\
\mathrm{e}_{\mathrm{c}}=\Lambda \Phi \Theta|0|=|\cos \lambda \cos \varphi| \\
|0||\sin \lambda \cos \varphi| \\
|1| \mid \sin \varphi
\end{array}
$$

The position vector can be expressed with the equation (A9).

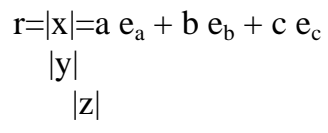

The gravity center of the ellipsoid can be represented with the equation (A10).

$\mathrm{R}_{0}=\left|\mathrm{X}_{0}\right|=(1 / \mathrm{N}) \sum_{\mathrm{i}=1}^{\mathrm{N}}\left|\mathrm{X}_{\mathrm{i}}\right|$

where $\mathrm{i}=1, \ldots, \mathrm{N}$

Then the second order moment around $\mathrm{x}, \mathrm{y}, \mathrm{z}$ axis in the extracted 3D image is expressed with the equation (A11).

$\iiint_{x^{2}} d x d y d z=\Delta S_{x x}$

$\iiint \mathrm{y}^{2} \mathrm{dx} d \mathrm{dy} \mathrm{dz}=\Delta \mathrm{S}_{\mathrm{yy}}$

$\iiint_{\mathrm{z}^{2}} \mathrm{dx} d \mathrm{dy} \mathrm{dz}=\Delta \mathrm{S}_{\mathrm{zz}}$

$\iiint_{x y} \mathrm{dx} d \mathrm{ydz}=\Delta \mathrm{S}_{\mathrm{xy}}$

$\iiint y z d x d y d z=\Delta S_{y z}$

$\iiint_{z x} d x d y d z=\Delta S_{z x}$

where

$\mathrm{S}_{\mathrm{xx}}=\sum_{\mathrm{i}=1}^{\mathrm{N}} \mathrm{X}_{\mathrm{i}}^{2}+\mathrm{N} \Delta_{\mathrm{x}}^{2} / 12$

$\mathrm{S}_{\mathrm{yy}}=\sum_{\mathrm{i}=1}^{\mathrm{N}} \mathrm{y}_{\mathrm{i}}^{2}+\mathrm{N} \Delta_{\mathrm{y}}{ }^{2} / 12$

$\mathrm{S}_{\mathrm{zz}}=\sum_{\mathrm{i}=1}^{\mathrm{N}} \mathrm{z}_{\mathrm{i}}^{2}+\mathrm{N} \Delta_{\mathrm{z}}^{2} / 12$

$\mathrm{S}_{\mathrm{xy}}=\sum_{\mathrm{i}=1}^{\mathrm{N}} \mathrm{x}_{\mathrm{i}} \mathrm{y}_{\mathrm{i}}$

$\mathrm{S}_{\mathrm{yz}}=\sum_{\mathrm{i}=1}^{\mathrm{N}} \mathrm{y}_{\mathrm{i}} \mathrm{z}_{\mathrm{i}}$

$\mathrm{S}_{\mathrm{Zx}}=\sum_{\mathrm{i}=1}^{\mathrm{N}} \mathrm{Z}_{\mathrm{i}} \mathrm{X}_{\mathrm{i}}$

The volume can be represented with the equation (A12).

$\int_{x i-\Delta x / 2}^{\mathrm{xi}+\Delta \mathrm{x} / 2} \int_{\mathrm{yi}-\Delta \mathrm{y} / 2}^{\mathrm{yi}+\Delta \mathrm{yi} / 2 \mathrm{zz} / 2} \int_{\mathrm{zi}-\Delta \mathrm{x} / 2 \mathrm{zi} / 2 \mathrm{y} / 2}^{\mathrm{zi}-\Delta \mathrm{z} / 2} \mathrm{x}^{2} \mathrm{dxdydz}=\Delta\left(\mathrm{x}_{\mathrm{i}}{ }^{2}+\Delta_{\mathrm{x}} / 12\right)$
$\int^{\mathrm{xi}+\Delta \mathrm{x} / 2} \int_{\mathrm{yi}+\Delta \mathrm{y} / 2}^{\mathrm{zi}+\Delta \mathrm{z} / 2} \mathrm{xydxdydz}=\Delta\left(\mathrm{x}_{\mathrm{i}} \mathrm{y}_{\mathrm{i}}\right)$ 
Then the volume and the second order moment of the ellipsoid are represented with the equation (A13).

$\mathrm{V}=\iiint \mathrm{dx} d \mathrm{~d} d \mathrm{z}=\mathrm{N} \Delta$

$\mathrm{M}_{0}=\iiint\left(\mathrm{x}^{2}+\mathrm{y}^{2}+\mathrm{z}^{2}\right) \mathrm{dx} \mathrm{dydz}=\mathrm{L}_{0} \Delta$

where $\mathrm{L}_{0}=\mathrm{S}_{\mathrm{xx}}+\mathrm{S}_{\mathrm{yy}}+\mathrm{S}_{\mathrm{zz}}$. Thus,

$\mathrm{A}^{2}+\mathrm{B}^{2}+\mathrm{C}^{2}=5 \mathrm{M}_{0} / \mathrm{V}$

Then the second order moment around $\mathrm{c}$ axis can be expressed with the equation (A15).

$\mathrm{M}_{\mathrm{c}}=\iiint\left(\mathrm{a}^{2}+\mathrm{b}^{2}+\mathrm{c}^{2}\right) \mathrm{da} \mathrm{db} \mathrm{dc}=\mathrm{M}_{0^{-}} \iiint \mathrm{c}^{2} \mathrm{da} \mathrm{db} \mathrm{dc}$

$=\mathrm{M}_{0}-\iiint\left(\mathrm{re} \mathrm{e}_{\mathrm{c}}\right)^{2} \mathrm{dx} \mathrm{dy} \mathrm{dz}$

$=\mathrm{M}_{0} \iiint\left\{\left(\mathrm{x}^{2} \cos ^{2} \lambda+\mathrm{y}^{2} \sin ^{2} \lambda+2 \mathrm{xy} \cos \lambda \sin \lambda\right) \cos ^{2} \varphi-\mathrm{z}^{2} \sin ^{2} \varphi\right.$

$-2(y z \sin \lambda+z x \cos \lambda) \cos \varphi \sin \varphi\} d x d y d z$

$\lambda$ and $\varphi$ are determined through minimization of the above moment as follows,

$\mathrm{L}_{\mathrm{c}}=\mathrm{M}_{\mathrm{c}} / \Delta$

$=\mathrm{L}_{0}-\left(\mathrm{S}_{\mathrm{xx}} \cos ^{2} \lambda+\mathrm{S}_{\mathrm{yy}} \sin ^{2} \lambda+2 \mathrm{~S}_{\mathrm{xy}} \cos \lambda \sin \lambda\right) \cos ^{2} \varphi-\mathrm{S}_{\mathrm{zz}} \sin ^{2} \varphi$

$-2\left(S_{y z} \sin \lambda+S_{z x} \cos \lambda\right) \cos \varphi \sin \varphi$

To minimize $L_{c}$, the following simultaneous equations have to be solved,

$\tan =\left\{\left(S_{x x}-S_{y y}\right) \sin (2 \lambda)-2 S_{x y} \cos (2 \lambda)\right\} /\left\{2\left(S_{y z} \cos \lambda-S_{z x} \sin \lambda\right)\right\}$

It is assumed the ranges of the angles are assumed as follows,

$-\pi<\lambda<\pi$

$0<\varphi<\pi / 2$

The minimum value of $L_{c}$ can be determined as follows,

$\mathrm{A}^{2}+\mathrm{B}^{2}=5 \mathrm{M}_{\mathrm{c}} / \mathrm{V}=5 \mathrm{~L}_{\mathrm{c}} / \mathrm{N}$

Thus, the radius in the direction of $\mathrm{c}$ axis is determined as follows,

$\mathrm{C}^{2}=5\left(\mathrm{~L}_{0}-\mathrm{L}_{\mathrm{c}}\right) / \mathrm{N}$

This is almost same thing for $a$ and $b$ axis. Let us assume the following parameters,

$\mathrm{h}=\mathrm{x} \sin \lambda-\mathrm{y} \cos \lambda$

$\mathrm{v}=(\mathrm{x} \cos \lambda+\mathrm{y} \sin \lambda) \sin \varphi-\mathrm{z} \cos \varphi$

The second order moments of $\mathrm{a}$ and $\mathrm{b}$ axis are determined as follows,

$\mathrm{M}_{\mathrm{a}}=\iiint\left(\mathrm{b}^{2}+\mathrm{c}^{2}\right) \mathrm{da} \mathrm{db} \mathrm{dc}=\mathrm{M}_{0^{-}} \iiint \mathrm{a}^{2} \mathrm{da} \mathrm{db} \mathrm{dc}$

$=\mathrm{M}_{0^{-}} \iiint\left(\mathrm{r} \mathrm{e}_{\mathrm{c}}\right)^{2} \mathrm{dxdydz}=\mathrm{M}_{0^{-}} \iiint(\mathrm{h} \cos \theta+\mathrm{v} \sin \theta)^{2} \mathrm{dxdy} \mathrm{dz}$

$=\mathrm{M}_{0}-\mathrm{L}_{\mathrm{ab}}(\theta) \Delta$

$\mathrm{M}_{\mathrm{b}}=\iiint\left(\mathrm{c}^{2}+\mathrm{a}^{2}\right) \mathrm{da} \mathrm{db} \mathrm{dc}=\mathrm{M}_{0^{-}} \iiint \mathrm{b}^{2} \mathrm{da} \mathrm{db} \mathrm{dc}$

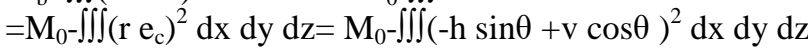

$=\mathrm{M}_{0}-\mathrm{L}_{\mathrm{ab}}(\theta \pm \pi / 2) \Delta$

(A21)

where

$\mathrm{L}_{\mathrm{ab}}(\theta)=\iiint(\mathrm{h} \cos \theta+\mathrm{v} \sin \theta)^{2} \mathrm{dxdydz} / \Delta$

$=\mathrm{S}_{\mathrm{hh}} \cos ^{2} \theta+\mathrm{S}_{\mathrm{vv}} \sin ^{2} \theta+\mathrm{S}_{\mathrm{hv}} \sin (2 \theta)$ and

$\mathrm{S}_{\mathrm{hh}}=\iiint(\mathrm{h})^{2} \mathrm{dx} \mathrm{dy} \mathrm{dz} / \Delta$

$\mathrm{S}_{\mathrm{hv}}=\iiint(\mathrm{hv})^{2} \mathrm{dxdydz} / \Delta$

$\mathrm{S}_{\mathrm{vv}}=\iiint(\mathrm{v})^{2} \mathrm{dx} d \mathrm{ydz} / \Delta$

Then

$\mathrm{S}_{\mathrm{hh}}=\mathrm{S}_{\mathrm{xx}} \sin ^{2} \lambda+\mathrm{S}_{\mathrm{yy}} \cos ^{2} \lambda-2 \mathrm{~S}_{\mathrm{xy}} \cos \lambda \sin \lambda$

$\mathrm{S}_{\mathrm{vv}}=\left(\mathrm{S}_{\mathrm{xx}} \cos ^{2} \lambda+\mathrm{S}_{\mathrm{yy}} \sin ^{2} \lambda-2 \mathrm{~S}_{\mathrm{xy}} \cos \lambda \sin \lambda\right) \sin ^{2} \varphi+\mathrm{S}_{\mathrm{zz}} \cos ^{2} \varphi$

$-2\left(S_{\mathrm{zx}} \cos \lambda+\mathrm{S}_{\mathrm{yz}} \sin \lambda\right) \cos \varphi \sin \varphi$

$S_{\mathrm{hv}}=\left\{\left(\mathrm{S}_{\mathrm{xx}}-\mathrm{S}_{\mathrm{yy}}\right) \cos \lambda \sin \lambda-\mathrm{S}_{\mathrm{xy}}\left(\cos ^{2} \lambda-\sin ^{2} \lambda\right)\right\} \sin \varphi$

$-\left(\mathrm{S}_{\mathrm{zx}} \sin \lambda-\mathrm{S}_{\mathrm{yz}} \cos \lambda\right) \cos \varphi$

$\theta$ can be determined through minimization of the second order moments around $\mathrm{a}$ and $\mathrm{b}$ axis which results in the following equation.

$\tan (2 \theta)=2 \mathrm{~S}_{\mathrm{hv}} /\left(\mathrm{S}_{\mathrm{hh}}-\mathrm{S}_{\mathrm{vv}}\right)$

The range of the angle is assumed as follows,

$0<\theta<\pi$

Then the followings are calculated as the result of the minimization.

$\mathrm{L}_{\mathrm{a}}=\mathrm{M}_{\mathrm{a}} / \Delta=\mathrm{L}_{0}-\mathrm{L}_{\mathrm{ab}}(\theta)$

$\mathrm{L}_{\mathrm{b}}=\mathrm{M}_{\mathrm{b}} / \Delta=\mathrm{L}_{0}-\mathrm{L}_{\mathrm{ab}}(\theta \pm \pi / 2)$

Also, the followings can be calculated.

$\mathrm{B}^{2}+\mathrm{C}^{2}=5 \mathrm{M}_{\mathrm{a}} / \mathrm{V}$

$\mathrm{C}^{2}+\mathrm{A}^{2}=5 \mathrm{M}_{\mathrm{b}} / \mathrm{V}$

Thus, the radius of $\mathrm{a}$ and $\mathrm{b}$ axis can be determined with the equation (A26).

$\mathrm{A}^{2}=5\left(\mathrm{~L}_{0}-\mathrm{L}_{\mathrm{a}}\right) / \mathrm{N}$

$\mathrm{B}^{2}=5\left(\mathrm{~L}_{0}-\mathrm{L}_{\mathrm{b}}\right) / \mathrm{N}$

Through these process, three parameters of the ellipsoidal model of eye are determined with the acquired eye and Purkinje images.

\section{ACKNOWLEDGMENT}

The authors would like to thank the fourth group members of the Department of Information Science, Saga University for their contribution to the experiments.

REFERENCES

[1] Kohei Arai and Kenro Yajima, Communication Aid and Computer Input System with Human Eyes Only, Electronics and Communications in Japan, Volume 93, Number 12, 2010, pages 1-9, John Wiley and Sons, Inc., 2010.

[2] Kohei Arai, Computer Input by Human Eyes Only and Its Applications, Intelligent Systems in Science and Information, 2014, Studies in Computer Intelligence, 591, 1-22, Springer Publishing Co. Ltd., 2015.

[3] Kohei Arai, Makoto Yamaura, Blink detection accuracy improvement by means of morphologic filter in designated key selection and determination for computer input by human eyes only. Journal of Image Electronics Society of Japan, 37, 5, 601-609, 2008

[4] Kohei Arai, Kenro Yajima, Communication aid system using computer input by human eyes only, Journal of Electric Society of Japan, Transaction C, 128-C,11,1679-1686, 2008

[5] Kohei Arai, Kenro Yajima, Communication aid system using computer input by human eyes only, Journal of Electric Society of Japan, Transaction C, 128-C,11,1679-1686, 2008 
[6] Djoko Purwanto, Ronny Mardiyanto, Kohei Arai, Electric wheel chair control with gaze detection and eye blinking, Proceedings of the International Symposium on Artificial Life and Robotics, GS9-4, 2009

[7] Djoko Purwanto, Ronny Mardiyanto and Kohei Arai, Electric wheel chair control with gaze detection and eye blinking, Artificial Life and Robotics, AROB Journal, 14, 694,397-400, 2009.

[8] Kohei Arai, Ronny Mardiyanto, Computer input by human eyes only with blink detection using Gabor filter, Journal of Visualization Society of Japan, 29, Suppl.2, 87-90, 2009

[9] Kohei Arai and Makoto Yamaura, Computer input with human eyes only using two Purkinje images which works in a real time basis without calibration, International Journal of Human Computer Interaction, 1, 3, 71-82, 2010

[10] Kohei Arai, Ronny Mardiyanto, A prototype of electric wheel chair control by eye only for paralyzed user, Journal of Robotics and Mechatronics, 23, 1, 66-75, 2010.

[11] Kohei Arai, Kenro Yajima, Robot arm utilized having meal support system based on computer input by human eyes only, International Journal of Human-Computer Interaction, 2, 1, 120-128, 2011

[12] Kohei Arai, Ronny Mardiyanto, Autonomous control of eye based electric wheel chair with obstacle avoidance and shortest path finding based on Dijkstra algorithm, International Journal of Advanced Computer Science and Applications, 2, 12, 19-25, 2011.

[13] Kohei Arai, Ronny Mardiyanto, Eye-based human-computer interaction allowing phoning, reading e-book/e-comic/e-learning, Internet browsing and TV information extraction, International Journal of Advanced Computer Science and Applications, 2, 12, 26-32, 2011

[14] Kohei Arai, Ronny Mardiyanto, Eye based electric wheel chair control system-I(eye) can control EWC-, International Journal of Advanced Computer Science and Applications, 2, 12, 98-105, 2011.

[15] Kohei Arai, Ronny Mardiyanto, Evaluation of users' impact for using the proposed eye based HCI with moving and fixed keyboard by using eeg signals, International Journal of Research and Reviews on Computer Science, 2, 6, 1228-1234, 2011.

[16] Kohei Arai, Ronny Mardiyanto, Electric wheel chair controlled by human eyes only with obstacle avoidance, International Journal of Research and Reviews on Computer Science, 2, 6, 1235-1242, 2011.

[17] K.Arai, R.Mardiyanto, Evaluation of users' impact for using the proposed eye based HCI with moving and fixed keyboard by using eeg signals, International Journal of Research and review on Computer Science, 2, 6, 1228-1234, 2012.

[18] K.Arai, R.Mardiyanto, Electric wheel chair controlled by human eyes only with obstacle avoidance, International Journal of Research and Review on Computer Science, 2, 6, 1235-1242, 2012.

[19] Kohei Arai, R.Mardiyanto, Robot arm control with human eyes only and its application to help having meal for patients, Journal of Electrical Engineering Society of Japan, Transaction C, C132, 3, 416-423, 2012.

[20] Kohei Arai, Human-Computer Interaction with human eyes only and its applications, Journal of Image Electronics Society of Japan, 41, 3, 296301, 2012.

[21] R.Mardiyanto, K.Arai, Eye-based Human Computer Interaction (HCI) A new keyboard for improving accuracy and minimizing fatigue effect, Scientific Journal Kursor, (ISSN 0216-0544), 6, 3, 1-4, 2012.
[22] K.Arai, R.Mardiyanto, Moving keyboard for eye-based Human Computer Interaction: HCI, Journal of Image and Electronics Society of Japan, 41, 4, 398-405, 2012.

[23] Kohei Arai, R.Mardiyanto, Service robot which is controlled by human eyes only with voice communication capability, Journal of Image Electronics Society of Japan, 41, 5, 535-542, 2012.

[24] Kohei Arai, Ronny Mardiyanto, Eye-based domestic robot allowing patient to be self-services and communications remotely, International Journal of Advanced Research in Artificial Intelligence, 2, 2, 29-33, 2013.

[25] Kohei Arai, Ronny Mardiaynto, Method for psychological status estimation by gaze location monitoring using eye-based HumanComputer Interaction, International Journal of Advanced Computer Science and Applications, 4, 3, 199-206, 2013.

[26] Kohei Arai, Kiyoshi Hasegawa, Method for psychological status monitoring with line of sight vector changes (Human eyes movements) detected with wearing glass, International Journal of Advanced Research in Artificial Intelligence, 2, 6, 65-70, 2013

[27] Kohei Arai, Wearable computing system with input output devices based on eye-based Human Computer Interaction: HCI allowing location based web services, International Journal of Advanced Research in Artificial Intelligence, 2, 8, 34-39, 2013.

[28] Kohei Arai Ronny Mardiyanto, Speed and vibration performance as well as obstacle avoidance performance of electric wheel chair controlled by human eyes only, International Journal of Advanced Research in Artificial Intelligence, 3, 1, 8-15, 2014.

[29] Kohei Arai, Service robot with communicational aid together with routing controlled by human eyes, Journal of Image Laboratory, 25, 6, 24-29, 2014

[30] Kohei Arai, Information collection service system by human eyes for disable persons, Journal of Image Laboratory, 25, 11, 1-7, 2014

[31] Kohei Arai, Relations between psychological status and eye movements, International Journal of Advanced Research on Artificial Intelligence, 4, 6, 16-22, 2015.

\section{AUTHORS PROFILE}

Kohei Arai, He received BS, MS and PhD degrees in 1972, 1974 and 1982, respectively. He was with The Institute for Industrial Science and Technology of the University of Tokyo from April 1974 to December 1978 also was with National Space Development Agency of Japan from January, 1979 to March, 1990. During from 1985 to 1987, he was with Canada Centre for Remote Sensing as a Post Doctoral Fellow of National Science and Engineering Research Council of Canada. He moved to Saga University as a Professor in Department of Information Science on April 1990. He was a councilor for the Aeronautics and Space related to the Technology Committee of the Ministry of Science and Technology during from 1998 to 2000. He was a councilor of Saga University for 2002 and 2003. He also was an executive councilor for the Remote Sensing Society of Japan for 2003 to 2005 . He is an Adjunct Professor of University of Arizona, USA since 1998. He also is Vice Chairman of the Commission "A" of ICSU/COSPAR for 8 years, 2008-2016 then he is now award committee member of ICSU/COSPAR. He wrote 37 books and published 570 journal papers. He received 30 of awards including ICSU/COSPAR Vikram Sarabhai Medal in 2016, and Science award of Ministry of Mister of Education of Japan in 2015. He is now Editor-in-Chief of IJACSA and IJISA. http://teagis.ip.is.saga-u.ac.jp/index.html 